Article

\title{
Fast Determination of Yttrium and Rare Earth Elements in Seawater by Inductively Coupled Plasma-Mass Spectrometry after Online Flow Injection Pretreatment
}

\author{
Zuhao Zhu and Airong Zheng * (iD \\ College of Ocean and Earth Sciences, Xiamen University, Xiamen 361102, China; zhz@stu.xmu.edu.cn \\ * Correspondence: arzheng@xmu.edu.cn; Tel.: +86-189-5928-8323
}

Received: 29 November 2017; Accepted: 26 January 2018; Published: 23 February 2018

\begin{abstract}
A method for daily monitoring of yttrium and rare earth elements (YREEs) in seawater using a cheap flow injection system online coupled to inductively coupled plasma-mass spectrometry is reported. Toyopearl AF Chelate $650 \mathrm{M}^{\circledR}$ resin permits separation and concentration of YREEs using a simple external calibration. A running cycle consumed $6 \mathrm{~mL}$ sample and took $5.3 \mathrm{~min}$, providing a throughput of 11 samples per hour. Linear ranges were up to $200 \mathrm{ng} \mathrm{kg}^{-1}$ except Tm $\left(100 \mathrm{ng} \mathrm{kg}^{-1}\right)$. The precision of the method was $<6 \%$ (RSDs, $n=5$ ), and recoveries ranged from $93 \%$ to $106 \%$. Limits of detection (LODs) were in the range $0.002 \mathrm{ng} \mathrm{kg}^{-1}$ (Tm) to $0.078 \mathrm{ng} \mathrm{kg}^{-1}$ (Ce). Good agreement between YREEs concentrations in CASS-4 and SLEW-3 obtained in this work and results from other studies was observed. The proposed method was applied to the determination of YREEs in seawater from the Jiulong River Estuary and the Taiwan Strait.
\end{abstract}

Keywords: rare earth elements; flow injection; inductively coupled plasma-mass spectrometry; seawater

\section{Introduction}

Due to their similar chemical properties, yttrium and fourteen rare earth elements ( $\mathrm{La}, \mathrm{Ce}, \mathrm{Pr}$, $\mathrm{Nd}, \mathrm{Sm}, \mathrm{Eu}, \mathrm{Gd}, \mathrm{Tb}, \mathrm{Dy}, \mathrm{Ho}, \mathrm{Er}, \mathrm{Tm}, \mathrm{Yb}, \mathrm{Lu}$ ), collectively named YREEs, have always been studied together. Rare earth elements have a narrow range of relative atomic weights, ranging from $138.91(\mathrm{La})$ to $173.04(\mathrm{Lu})$, which results in extremely coherent chemical properties [1,2]. YREEs in seawater are drawing increasing attention due to the following aspects: (1) YREEs can be used as powerful tracers in marine biogeochemistry (ocean circulation, scavenging processes, trace metal cycles, etc.) and the redox-sensitive nature of $\mathrm{Ce}$ and Eu make them valuable for oxidation-reduction reactions [1-6]; (2) as YREEs are analogues of the radioactive actinides, understanding the geochemical cycling of YREEs can provide clues on the behavior of actinides (Am and $\mathrm{Cm}$ ), which is important for monitoring the migration of actinides in radioactive waste repositories [7,8]; and (3) YREEs are widely used in industry (superconductor, functional materials, etc.), medical diagnostics (MRI, magnetic resonance imaging) and agriculture (as fertilizer) [9-14]. Anomalous concentrations of Gd, La and Sm discovered in estuarine and coastal seawaters reveals that the risks of YREEs' release into the ocean through runoff and sewage are increasing, threatening marine ecosystems and altering the distribution patterns of YREEs in estuaries and oceans [2,9-14]. Therefore, it is of great interest to monitor YREEs in seawater.

However, quickly and accurately determining the concentration of YREEs in seawater is a challenge because of their low concentrations and high salt matrix. The emergence of inductively coupled plasma-mass spectrometry (ICP-MS) has made trace and multi-element analysis more readily available and has been commonly used for the determination of YREEs. Nevertheless, little tolerance to total dissolved solids $(<0.1 \%)$ makes direct (or after dilution) determinations of YREEs in seawater 
by ICP-MS inadvisable, since large amounts of salts will not only cause clogging of nebulizer, torch and cones, leading to signal drift, but also introduce severe polyatomic interferences. Thus YREEs must be separated and concentrated before detection. As pretreatment procedures, liquid-liquid extraction [5,15-17], co-precipitation [18-21], and solid-phase extraction [22-27] techniques have been utilized. Among these procedures, solid-phase extraction using chelating absorbents is becoming popular due to its wide selectivity of YREEs, low risk of contamination, freedom from toxic reagents and its simplicity for interfacing with ICP-MS to permit online determination when using flow injection (FI) as sample preconcentration systems. Compared to offline determination (batch method), online approaches using FI-ICP-MS has the advantages of sensitive response, high sample throughput, small volumes consumption of sample and reagents, little risk of contamination and labor savings [9,12,28-36]. The commercially available FIAS-400 (Perkin-Elmer, Waltham, MA, USA) [29,31-33] and SeaFAST (Elemental Scientific, Omaha, NE, USA) [36] FI system has been used in many studies devoted to the development of online determination of YREEs in seawater when coupled with ICP-MS. However, the relative high expense for a typical ICP-MS lab has restricted their wide application. Amongst the various absorbents used for FI-ICP-MS, Toyopearl AF Chelate $650 \mathrm{M}^{\circledR}$ resin, featuring iminodiacetate functional groups, can sequester all YREEs and offers stability (no shrinkage of the resin under both strong acid and high salt environments), while remaining inexpensive and commercially available [31,37-39]. Although Willie and Sturgeon [31] applied this resin for the online determination of YREEs in seawater using FI-ICP-TOF-MS, the relatively high LODs and the poor sample throughput $\left(5 \mathrm{~h}^{-1}\right)$ were not attractive for routine measurements.

In this study, based on previous work $[40,41]$, Toyopearl AF Chelate $650 \mathrm{M}^{\circledR}$ resin was used to separate YREEs from seawater and a fast FI-ICP-MS method for the online determination of YREEs in seawater was established. The FI system was readily set-up and automated to ensure ease of operation, as well as much cheaper than the FIAS- 400 and SeaFAST. Experimental parameters were investigated and optimized to minimize sample consumption and improve the LODs. Finally, the developed method was used for the determination of YREEs in estuarine and coastal seawaters.

\section{Results and Discussion}

\subsection{Effects of Sample Loading Rate and Time}

The sample loading rate and time determine the volume of sample analyzed. To optimize the sample loading rate, $7.5 \mathrm{~mL}$ seawater (salinity $=33$ ) was processed through the minicolumn using flow rates ranging from 1.5 to $4.0 \mathrm{~mL} \mathrm{~min}^{-1}$. For all YREEs, it was found that peak areas decreased with increasing loading rate. When the loading rate was $2.0 \mathrm{~mL} \mathrm{~min}^{-1}$, response from Ce dropped the most, to about $89 \%$ (Supplementary Information Table S1) of the peak area achieved at $1.5 \mathrm{~mL} \mathrm{~min}{ }^{-1}$ (generally the rate of sample passing a column packed with Toyopearl AF Chelate $650 \mathrm{M}^{\circledR}$ resin by gravity is $1.5 \mathrm{~mL} \mathrm{~min}^{-1}$, under which the YREEs can be $100 \%$ retained). Taking the analysis time and retention efficiency into consideration, $2.0 \mathrm{~mL} \mathrm{~min}^{-1}$ was subsequently used as the loading rate.

Theoretically, the peak area response should increase linearly with loading time. In this study, loading times from $120 \mathrm{~s}$ to $540 \mathrm{~s}$ were examined, with results showing that the relative coefficient $\left(R^{2}\right)$ between the peak areas and loading times were all $>0.9934$ for all YREEs over the entire time range (Supplementary Information Table S2), indicating that the capacity of the minicolumn would not be overloaded even by processing $18 \mathrm{~mL}$ of high salinity seawater. In order to shorten the running time and improve throughput, $180 \mathrm{~s}$ was selected as the sample loading time, i.e., $6 \mathrm{~mL}$ sample was consumed. Loading time can be extended if the YREEs concentrations are significantly lower.

\subsection{Influence of Interferences and Effect of Rinsing Conditions}

Although ICP-MS detect YREEs may suffer from polyatomic interference, proper selection of target isotopes may help minimize such effects. However, interferences from lower REE oxides such as ${ }^{143} \mathrm{Nd}^{16} \mathrm{O}^{+}$on ${ }^{159} \mathrm{~Tb},{ }^{147} \mathrm{Sm}^{16} \mathrm{O}^{+}$on ${ }^{163} \mathrm{Dy},{ }^{149} \mathrm{Sm}^{16} \mathrm{O}^{+}$on ${ }^{165} \mathrm{Ho},{ }^{150} \mathrm{Nd}^{16} \mathrm{O}^{+}$and ${ }^{150} \mathrm{Sm}^{16} \mathrm{O}^{+}$on ${ }^{166} \mathrm{Er}$, 
${ }^{153} \mathrm{Eu}^{16} \mathrm{O}^{+}$on ${ }^{169} \mathrm{Tm},{ }^{159} \mathrm{~Tb}^{16} \mathrm{O}^{+}$on ${ }^{175} \mathrm{Lu}$ are inevitable. Nevertheless, the oxide level was minimized during the tuning step by optimizing the ICP-MS parameters to ensure ${ }^{140} \mathrm{Ce}^{16} \mathrm{O} /{ }^{140} \mathrm{Ce}<2 \%$, plus the concentration variances of YREEs are generally within one order of magnitude, thus corrections for interference caused by light YREEs oxides were not considered, and polyatomic interferences such as ${ }^{131} \mathrm{Ru}^{16} \mathrm{O}^{+}$on ${ }^{147} \mathrm{Sm},{ }^{140} \mathrm{Ce}^{35} \mathrm{Cl}^{+}$on ${ }^{175} \mathrm{Lu}$, and ${ }^{135} \mathrm{Ba}^{16} \mathrm{O}^{+}$on ${ }^{151} \mathrm{Eu}$ can be overcome using collision gas (He) mode $[26,31,33]$.

However, physical interference induced by the salt matrix on instrument should also be resolved, since large amounts of salts (e.g., $\mathrm{Na}^{+}, \mathrm{K}^{+}, \mathrm{Ca}^{2+}, \mathrm{Cl}^{-}$) may deposit on the torch and the cones of the ICP-MS to cause considerable signal depression and drift in YREEs response. After sample loading, a mixture of buffer solution and ultrapure water was passed through the minicolumn to remove the residual salts. The flow rate was the same as the loading rate $\left(2.0 \mathrm{~mL} \mathrm{~min}^{-1}\right)$ to reduce flow pulses in the minicolumn and the rinse time ranged from 30 to $70 \mathrm{~s}$ was studied. To minimize the rinse time, a test sample of salinity 33 was processed and response of $\mathrm{Na}, \mathrm{Mg}, \mathrm{Cl}, \mathrm{Ba}$ and the YREEs were monitored. The relative peak areas (\%) of each elements using rinsing time $40-70 \mathrm{~s}$ to $30 \mathrm{~s}$ are shown in Figure 1. With a rinsing time of $60 \mathrm{~s}$, peak areas of $\mathrm{Na}, \mathrm{Mg}$ and $\mathrm{Cl}$ decreased to $39 \%, 36 \%$ and $35 \%$, respectively. While no significant decrease in peak area was observed with a further $10 \mathrm{~s}$ rinsing. The peak areas of Ba were nearly the same as the procedural blank, demonstrating that $\mathrm{Ba}$ in the seawater was not retained by the minicolumn, such that its interferences were negligible. All YREEs were approximately $100 \%$ recovered irrespective of the rinse time range. Consequently, $60 \mathrm{~s}$ was determined to be the optimal rinse time.

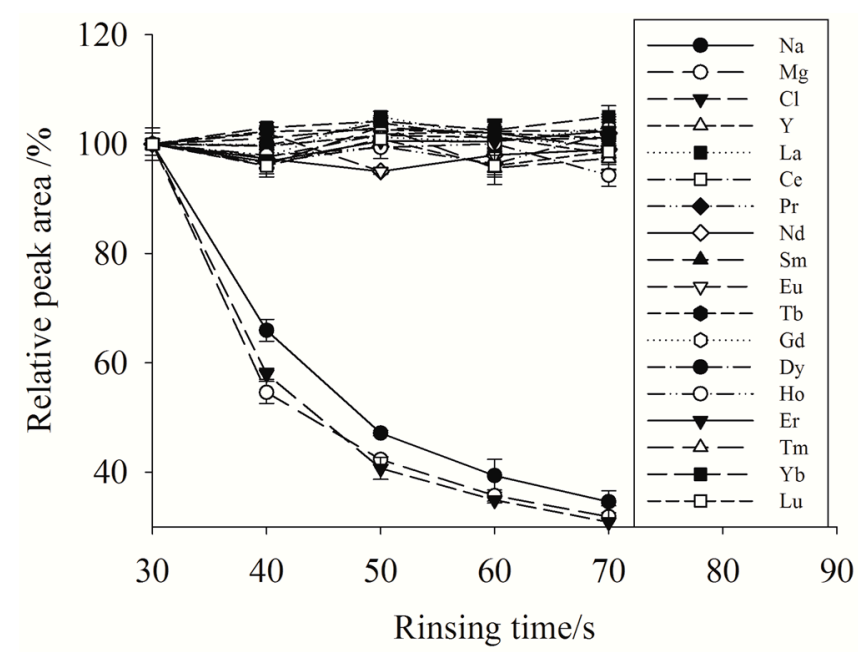

Figure 1. Effect of rinse time on $\mathrm{Na}, \mathrm{Mg}, \mathrm{Cl}$ and YREEs peak areas; test sample salinity $=33$. The relative peak areas were normalized to that obtained using a rinsing time of $30 \mathrm{~s}$.

\subsection{Effects of Eluting Condition}

To ensure the retained YREEs were totally eluted, the concentration of eluent $\left(\mathrm{HNO}_{3}\right)$ and elution rate and time were optimized. Results for $\mathrm{La}, \mathrm{Gd}$ and $\mathrm{Yb}$ are shown in Figures 2 and 3 as examples. The concentrations of $\mathrm{HNO}_{3}$ used ranged from 0.5 to $2.0 \mathrm{~mol} \mathrm{~L}^{-1}$. The results showed that there were no significant differences between the peak shapes for the various $\mathrm{HNO}_{3}$ concentrations (Figure 2) with the result that $0.8 \mathrm{~mol} \mathrm{~L}^{-1} \mathrm{HNO}_{3}$ was selected as the eluent since $0.5 \mathrm{~mol} \mathrm{~L}^{-1} \mathrm{HNO}_{3}$ is not strong enough to elute all sequestered trace metals which will stay on the column and compete with YREEs from the next sample to chelate with the resin. While more concentrated $\mathrm{HNO}_{3}$ than $0.8 \mathrm{~mol} \mathrm{~L}^{-1}$ was not considered to protect ICP-MS, and our study showed that when used $0.8 \mathrm{~mol} \mathrm{~L}^{-1} \mathrm{HNO}_{3}$ as the eluting acid, the retention efficiency of the column would not decrease after 400 runs. As for

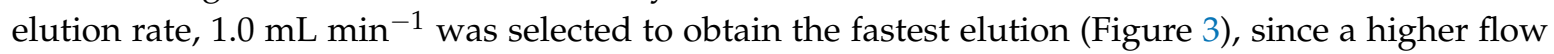


rate may lead to instability of the plasma. With eluting use $0.8 \mathrm{~mol} \mathrm{~L}^{-1} \mathrm{HNO}_{3}$ under a flow rate of $1.0 \mathrm{~mL} \mathrm{~min}^{-1}, 50 \mathrm{~s}$ was required to elute all YREEs.

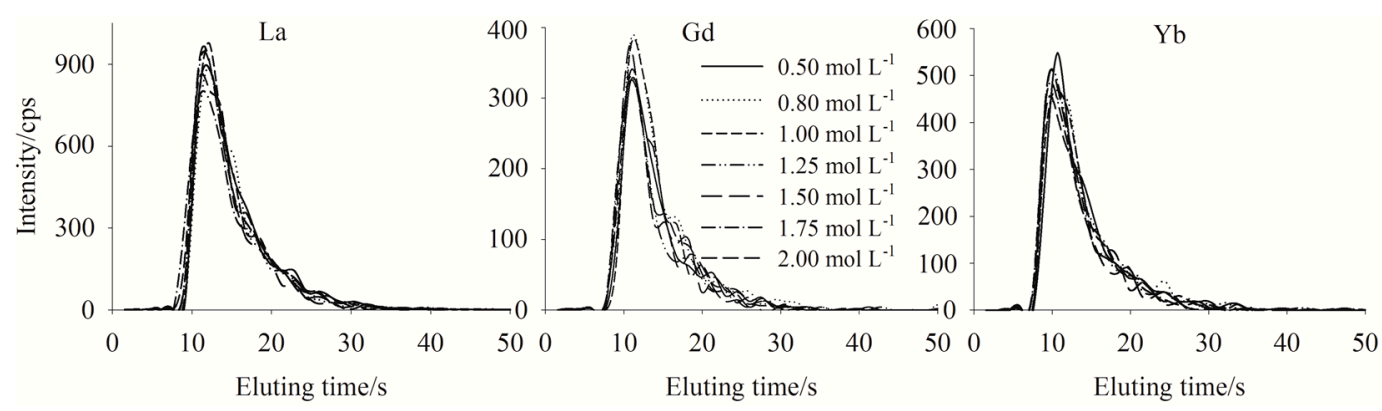

Figure 2. Elution profiles for $\mathrm{La}, \mathrm{Gd}$ and $\mathrm{Yb}$ when eluted with different concentrations of $\mathrm{HNO}_{3}$; test sample salinity $=33$.

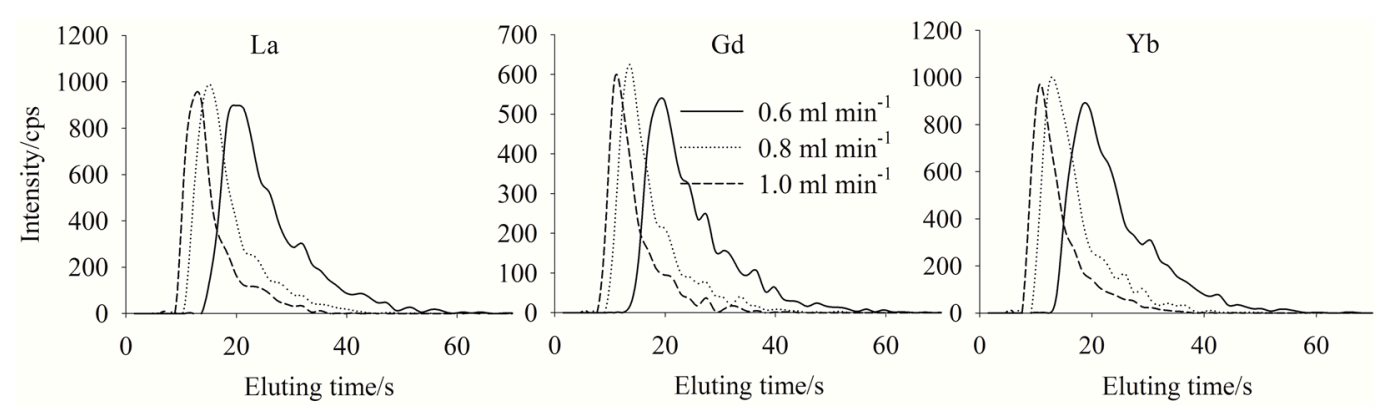

Figure 3. Elution profiles for $\mathrm{Y}$ when eluted with $0.8 \mathrm{~mol} \mathrm{~L}^{-1} \mathrm{HNO}_{3}$ at different flow rates; test sample salinity $=33$.

\subsection{Calibration and Effect of Salinity}

When analyzing high matrix samples, the method of standard addition is often used for quantification to compensate for matrix effects. However, this methodology is tedious and labor intensive. Research by Willie and Sturgeon [31] concluded that the recoveries of YREEs from seawater using Toyopearl AF Chelate $650 \mathrm{M}^{\circledR}$ resin were independent of the salinity, and many studies have utilized a simple external calibration based on dilute $\mathrm{HNO}_{3}$ for quantification. To confirm this conclusion and expand the simple calibration to seawater samples having a wide range of salinities (i.e., estuarine waters), four calibration curves $\left(0-10 \mathrm{ng} \mathrm{kg}^{-1}\right)$ based on four different matrices $\left(0.02 \mathrm{~mol} \mathrm{~L}^{-1}\right.$ $\mathrm{HNO}_{3}$, estuarine water sample with salinities of 2, 15 and 33) were prepared and analyzed using FI-ICP-MS. All four samples were using standard additions methodology (briefly, YREEs working standards were added to separate aliquots of a sample, and then the standard-containing samples plus the original sample were analyzed using FI-ICP-MS). The four calibration curves for $\mathrm{Y}$ are displayed in Figure 4 as an example.

The slopes of the four curves for each YREEs were tested for significant difference by SPSS (IBM SPSS Statistics 19.0, New York, NY, USA) using covariance analysis and all achieved a $\sigma$ score (probability value) $>0.05$ (confidence level), indicating that the four slopes were not statistically different, demonstrating that the retention and elution properties of Toyopearl AF Chelate $650 \mathrm{M}^{\circledR}$ were not influenced by salinity. YREEs concentrations were thus calculated using external calibration curves comprising a $0.02 \mathrm{~mol} \mathrm{~L}^{-1} \mathrm{HNO}_{3}$ as the matrix. 


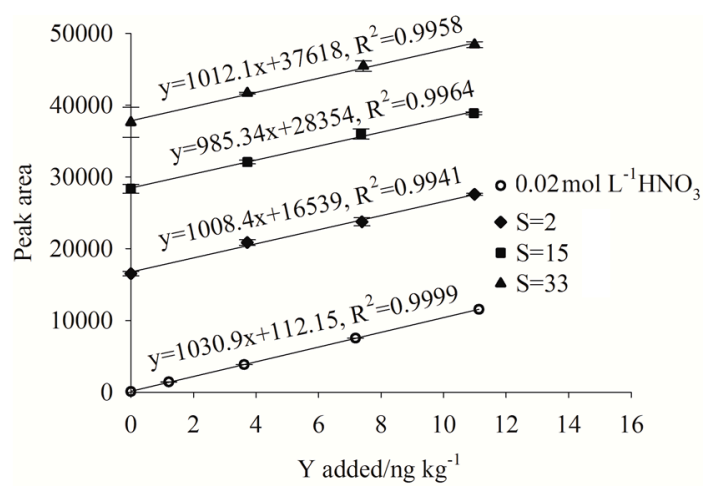

Figure 4. Standard additions calibration curves for $\mathrm{Y}$ based on samples having different matrices.

\subsection{Analytical Figures of Merit}

Using the optimized conditions, about $5.3 \mathrm{~min}$ was required for processing a $6 \mathrm{~mL}$ sample, resulting in a sample throughput of $11 \mathrm{~h}^{-1}$. The linear range of the method was examined using a ten-point external calibration curve with concentrations from 0 to $200 \mathrm{ng} \mathrm{kg}^{-1}$. The $\mathrm{R}^{2}$ of the 7 ranges $\left(0-5,0-7,0-15,0-25,0-50,0-100\right.$ and $\left.0-200 \mathrm{ng} \mathrm{kg}^{-1}\right)$ were all larger than 0.9917 (except for Tm, the $\mathrm{R}^{2}$ of which was 0.9479 for the $0-200 \mathrm{ng} \mathrm{kg}^{-1}$ range). Covariance analysis was used to investigate the significant difference between the slopes of the 7 curves. Results showed the $\sigma$ scores for all YREEs $>0.05$ (excepted Tm in 0-200 $\mathrm{ng} \mathrm{kg}^{-1}$ range), indicating no significant differences between the 7 slopes for each YREEs. Therefore, the developed FI-ICP-MS procedure was capable of accurate measurements of YREEs concentration up to $200 \mathrm{ng} \mathrm{kg}^{-1}$ (100 $\mathrm{ng} \mathrm{kg}^{-1}$ for Tm), suitable for the determination of YREEs in almost all seawater samples.

The precision and accuracy of the method were also examined using samples having differing salinities (salinity $=2,15$ and 33). The repeatability and reproducibility of the method was evaluated via repetitive inter-day $(n=5)$ and separate-day $(n=4)$ measurements of three samples, with inter-day RSDs of $0.3-6 \%$ and separate-day RSDs of $2-8 \%$. Spike recovery testing was conducted and recoveries of $93-106 \%$ were obtained, confirming the accuracy of the method. Also we tested the performance of the method by analysis some high salinity aged seawater sample (salinity $=35-40$, to simulate open ocean water with low level dissolved organic matter), and better RSDs of $0.47-4.81 \%$ and recovery of $94.5-104 \%$ were obtained, likely due to the aged seawater contained much less dissolved organic matter, which may compete with YREEs to absorb on the resin or compete with the resin to absorb the YREEs, than the estuarine and coastal seawater. These results suggested that the developed method provides satisfactory analytical results for seawater with wide range salinity.

Although Certified Reference Materials for YREEs in seawater (like newly released NASS-7 and some GEOTRACES intercalibration reference materials) were not commercially available at the time of this study, compiled results of multiple reports on YREE concentrations in CASS-4 and SLEW- 3 can provide valuable reference data for the validation of the methodology developed in this study [35]. Such reference data, plus that obtained in this study are summarized in Table 1.

The data show good agreement with other studies (except the Y, Sm, Gd, Ho and Tm in CASS-4, whose RSD of this study value and the reference compiled were $>5 \%$ ), indicating the proposed method can provide reliable YREEs concentrations in estuarine and coastal seawater. As to the durability of the minicolumn, no decrease of YREEs retention efficiency was detected after 400 runs.

The procedural blank was obtained by processing $0.02 \mathrm{~mol} \mathrm{~L}^{-1} \mathrm{HNO}_{3}(\mathrm{pH} \sim 1.6)$. The LODs of this FI-ICP-MS system were calculated based on $3 \mathrm{~s}$ (standard deviation) of 11 procedure blanks. The results are shown in Table 2. The blank and LODs are sufficiently low to permit determination of YREEs in estuarine and coastal seawaters. However if the open ocean seawater was subject to analysis, the $\mathrm{HNO}_{3}$ and the buffer should be further purified to reduce the procedure blank. For the $\mathrm{HNO}_{3}$, a second or 
even more times of distillation can be adopted, while for the buffer an additional minicolumn packed with Toyopearl AF Chelate $650 \mathrm{M}^{\circledR}$ resin placed on the buffer line can be implemented.

Table 1. YREEs concentrations in CASS-4 (Salinity $=30.7)$ and SLEW-3 (Salinity $=15)$ from references and this study.

\begin{tabular}{|c|c|c|c|c|c|c|}
\hline \multirow{2}{*}{ Elements } & \multicolumn{3}{|c|}{ CASS-4 (ng kg ${ }^{-1}$ ) } & \multicolumn{3}{|c|}{ SLEW-3 (ng kg $\left.{ }^{-1}\right)$} \\
\hline & $\begin{array}{c}\text { Reference } \\
\text { Compiled a }\end{array}$ & This Study ${ }^{b}$ & $\operatorname{RSD}^{c}(\%)$ & $\begin{array}{l}\text { Reference } \\
\text { Compiled } \mathrm{d}\end{array}$ & This Study ${ }^{b}$ & $\operatorname{RSD}^{\mathrm{c}}(\%)$ \\
\hline $\mathrm{Y}$ & $20.93 \pm 0.40$ & $18.89 \pm 0.12$ & 7.25 & $40.55 \pm 2.05$ & $38.10 \pm 2.39$ & 4.41 \\
\hline $\mathrm{La}$ & $9.37 \pm 0.38$ & $9.96 \pm 0.15$ & 4.33 & $7.80 \pm 0.13$ & $8.22 \pm 0.25$ & 3.71 \\
\hline $\mathrm{Ce}$ & $4.69 \pm 0.92$ & $4.90 \pm 0.07$ & 3.13 & $7.08 \pm 0.68$ & $7.19 \pm 0.45$ & 1.06 \\
\hline $\operatorname{Pr}$ & $1.33 \pm 0.06$ & $1.37 \pm 0.01$ & 2.10 & $1.68 \pm 0.05$ & $1.64 \pm 0.03$ & 1.78 \\
\hline $\mathrm{Nd}$ & $5.39 \pm 0.47$ & $5.49 \pm 0.04$ & 1.30 & $8.18 \pm 0.35$ & $7.97 \pm 0.19$ & 1.82 \\
\hline Sm & $5.55 \pm 0.17$ & $6.00 \pm 0.21$ & 5.45 & $7.10 \pm 0.15$ & $7.38 \pm 0.21$ & 2.69 \\
\hline $\mathrm{Eu}$ & $0.23 \pm 0.03$ & $0.23 \pm 0.02$ & 0.00 & $0.54 \pm 0.08$ & $0.55 \pm 0.02$ & 1.72 \\
\hline $\mathrm{Gd}$ & $1.29 \pm 0.1$ & $1.46 \pm 0.04$ & 8.74 & $3.09 \pm 0.01$ & $3.20 \pm 0.06$ & 2.36 \\
\hline $\mathrm{Tb}$ & $0.20 \pm 0.03$ & $0.20 \pm 0.01$ & 0.00 & $0.45 \pm 0$ & $0.43 \pm 0.02$ & 2.94 \\
\hline Dy & $1.41 \pm 0.08$ & $1.42 \pm 0.05$ & 0.38 & $3.37 \pm 0.02$ & $3.33 \pm 0.08$ & 0.95 \\
\hline Ho & $0.38 \pm 0.05$ & $0.35 \pm 0.02$ & 6.32 & $0.91 \pm 0$ & $0.91 \pm 0.07$ & 0.13 \\
\hline Er & $1.20 \pm 0.1$ & $1.27 \pm 0.08$ & 4.15 & $2.71 \pm 0.01$ & $2.78 \pm 0.05$ & 1.72 \\
\hline $\mathrm{Tm}$ & $0.23 \pm 0.07$ & $0.20 \pm 0.02$ & 10.75 & $0.37 \pm 0$ & $0.35 \pm 0.01$ & 3.93 \\
\hline $\mathrm{Yb}$ & $1.21 \pm 0.14$ & $1.16 \pm 0.01$ & 3.29 & $1.95 \pm 0.14$ & $1.85 \pm 0.06$ & 3.85 \\
\hline $\mathrm{Lu}$ & $0.20 \pm 0.03$ & $0.19 \pm 0.01$ & 4.56 & $0.31 \pm 0.03$ & $0.30 \pm 0.01$ & 3.51 \\
\hline
\end{tabular}

${ }^{\mathrm{a}}$ Mean \pm 1 standard deviation, $n=6$, based on results in references [16,19-21,25,27]; ${ }^{\mathrm{b}}$ Mean \pm 1 standard deviation, $n=5 ;{ }^{\mathrm{c}}$ Relative standard deviation of this study from the data of reference compiled; ${ }^{\mathrm{d}}$ Mean \pm 1 standard deviation, $n=3$, based on results in references $[16,19]$.

Table 2. Procedural blanks and LODs.

\begin{tabular}{ccc}
\hline Elements & Blank $^{\mathbf{a}}\left(\mathbf{n g} \mathbf{~ k g}^{\mathbf{- 1}}\right)$ & LODs $\left(\mathbf{n g} \mathbf{~ k g}^{\mathbf{- 1}}\right)$ \\
\hline Y & $0.126 \pm 0.023$ & 0.034 \\
$\mathrm{La}$ & $0.172 \pm 0.05$ & 0.045 \\
$\mathrm{Ce}$ & $0.61 \pm 0.112$ & 0.078 \\
$\mathrm{Pr}$ & $0.038 \pm 0.023$ & 0.019 \\
$\mathrm{Nd}$ & $0.124 \pm 0.038$ & 0.048 \\
$\mathrm{Sm}$ & $0.046 \pm 0.021$ & 0.027 \\
$\mathrm{Eu}$ & $0.007 \pm 0.004$ & 0.009 \\
$\mathrm{Gd}$ & $0.05 \pm 0.01$ & 0.022 \\
$\mathrm{~Tb}$ & $0.007 \pm 0.003$ & 0.003 \\
$\mathrm{Dy}$ & $0.03 \pm 0.007$ & 0.021 \\
$\mathrm{Ho}$ & $0.006 \pm 0.003$ & 0.003 \\
$\mathrm{Er}$ & $0.02 \pm 0.007$ & 0.012 \\
$\mathrm{Tm}$ & $0.003 \pm 0.003$ & 0.002 \\
$\mathrm{Yb}$ & $0.009 \pm 0.007$ & 0.005 \\
$\mathrm{Lu}$ & $0.002 \pm 0.002$ & 0.002 \\
\hline
\end{tabular}

${ }^{\mathrm{a}}$ Mean \pm 1 standard deviation, $n=5$.

\subsection{Comparison with Other FI-ICP-MS Systems}

Figures of merit of the developed FI-ICP-MS procedures are summarized in Table 3. Compared with other FI systems, this arrangement is easy to construct and short sample duration to ensure high sample throughput $\left(11 \mathrm{~h}^{-1}\right)$, and provided excellent LODs based on only $6 \mathrm{~mL}$ sample consumption, moreover the total cost of this FI system is only about $20 \%$ of the cost of FIAS-400 (let alone the much more expensive seaFAST), making the daily and large scale determination of YREEs in seawater samples relatively inexpensive in a regular ICM-MS lab. Though report of Benkhedda et al. [30] 
indicated shorter duration (4 min) and less sample consumption than this study, but an ICP-TOF-MS was required and the separation unit based on a knotted reactor was not as easily prepared as a minicolumn used here; results of Wang et al. [34] had the shortest duration (2.8 $\mathrm{min}$ ) amongst all arrangements, while much more sample was needed and the fast loading rate may risk decreased retention efficiency and pump tubing aging. Advantages of this work were especially obviously when compared with thetudy of Willie and Sturgeon [31], in which the same Toyopearl AF Chelate $650 \mathrm{M}^{\circledR}$ absorbent was used, while the sensitivity provided by the ICP-TOF-MS was much lower than the quadrupole ICP-MS used in our work.

\subsection{Applications}

The established method was used for the determination of YREEs in seawater collected from the Jiulong River Estuary and the Taiwan Strait. Results are presented in Supplementary Information Tables S3 and S4. Post-Archean Australian Shales (PAAS) [42] normalized YREEs distributions patterns of the Jiulong River Estuary and the Taiwan Strait are plotted in Figure 5.
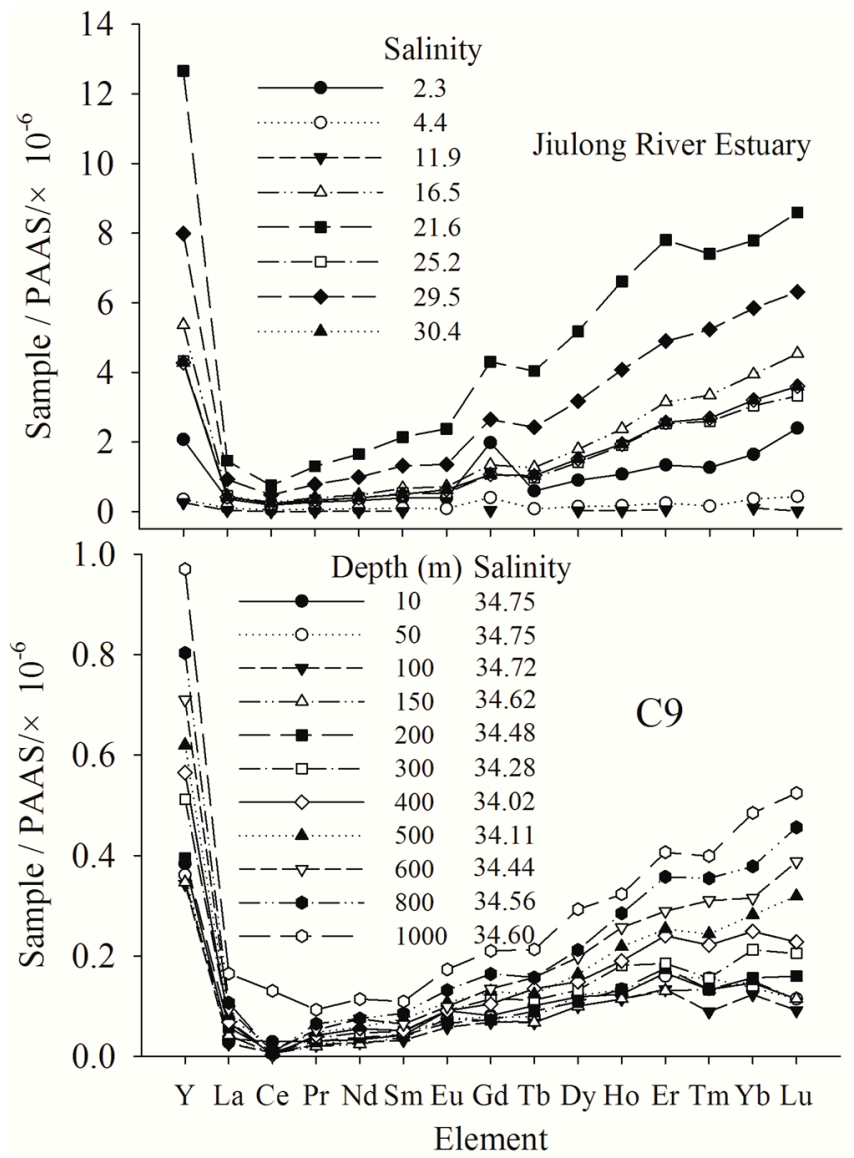

Figure 5. PAAS normalized YREEs patterns in surface water of Jiulong River Estuary and in station C9 $\left(22^{\circ} 07^{\prime} 13^{\prime \prime} \mathrm{N}, 118^{\circ} 24^{\prime} 41^{\prime \prime}\right.$ E) of Taiwan Strait.

Relatively flat YREEs patterns were observed in samples having salinities of 4.4 and 11.9 from the Jiulong River Estuary, while all YREEs patterns show obviously negative Ce anomaly and positive Gd anomaly (except salinity 11.9). The latter could be attributed to anthropogenic Gd discharge (e.g., MRI contrast reagent). In the seawater of Taiwan Strait, slightly negative Ce anomalies were obtained from the YREEs patterns (except the surface and bottom water), which are commonly observed in the world oceans [6]. The geochemistry of YREEs in the Jiulong River Estuary and the Taiwan Strait will be further studied in future work. 
Table 3. Comparison with other FI-ICP-MS methodologies for the determination of YREEs in seawater.

\begin{tabular}{|c|c|c|c|c|c|c|c|c|}
\hline \multirow{2}{*}{$\begin{array}{c}\text { Loading } \\
\text { Rate }\left(\mathrm{mL} \mathrm{min}^{-1}\right)\end{array}$} & \multicolumn{3}{|c|}{ Eluting } & \multirow{2}{*}{ Duration (min) } & \multirow{2}{*}{ Absorbent } & \multirow{2}{*}{ Sample (mL) } & \multirow{2}{*}{ LODs (ng kg ${ }^{-1}$ ) } & \multirow{2}{*}{ Reference } \\
\hline & Rate $\left(\mathrm{mL} \min ^{-1}\right)$ & Time (s) & $\mathrm{HNO}_{3}\left(\mathrm{~mol} \mathrm{~L}^{-1}\right)$ & & & & & \\
\hline 5 & 1.2 & 80 & 1.0 & $\sim 5.5$ & $-a^{a}$ & 10 & $0.06-0.27$ & [8] \\
\hline 12 & 1.5 & 300 & 2.0 & $\sim 12$ & $\begin{array}{c}\text { Amberlite } \\
\text { XAD-7 + 8HQ }\end{array}$ & 100 & $0.002-0.016^{\mathrm{b}}$ & [9] \\
\hline 2.0 & 1.0 & 30 & 0.1 & $>30$ & APAR $^{c}$ & 60 & $0.001-0.013$ & [12] \\
\hline 2 & 1.0 & 100 & $0.8^{\mathrm{d}}$ & $\sim 9.5$ & $\mathrm{I}-8-\mathrm{HQ}^{\mathrm{e}}$ & 3 & $0.06-0.6$ & [29] \\
\hline 4.4 & 0.8 & 90 & 0.4 & $\sim 4$ & $\mathrm{PMBP}^{\mathrm{f}}$ & 2.2 & $0.003-0.04$ & [30] \\
\hline 5 & 1.5 & 30 & 1.5 & 12 & $\begin{array}{c}\text { Toyopearl AF } \\
\text { Chelate } 650 \mathrm{M}^{\circledR}\end{array}$ & 50 & $0.02-0.29$ & [31] \\
\hline 3.2 & 1.7 & 61 & 1.0 & 7 & Muromac A-1 & 6.4 & $0.04-0.251$ & {$[32]$} \\
\hline 3.2 & 2.0 & 60 & 1.4 & 7 & MAF-8HQ ${ }^{g}$ & 6.4 & $0.11-0.30$ & [33] \\
\hline 7.4 & 0.5 & 35 & 0.9 & 2.8 & M-PTFE ${ }^{h}$ & 14.8 & $0.001-0.02$ & [34] \\
\hline 5 & 0.5 & 120 & 2 & 6 & $\begin{array}{c}\text { Nobias chelate } \\
\text { PB1M }\end{array}$ & 10 & $0.005-0.09$ & [35] \\
\hline 1.0 & 0.3 & 5 & $1.5^{\mathrm{i}}$ & 15 & - & 7 & $0.001-0.036$ & [36] \\
\hline 2.0 & 1.0 & 60 & 0.8 & $\sim 5.3$ & $\begin{array}{c}\text { Toyopearl AF } \\
\text { Chelate } 650 \mathrm{M}^{\circledR}\end{array}$ & 6 & $0.002-0.078$ & This study \\
\hline
\end{tabular}

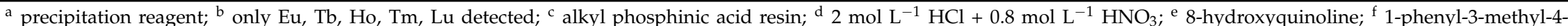
benzoylpyrazol-5-one; ' 8 8-quinoline-immoblized fluorinated metal alkoxide glass; ${ }^{\mathrm{h}}$ polytetrafluoroethylene; ${ }^{\mathrm{i}} 1.5 \mathrm{~mol} \mathrm{\textrm {L } ^ { - 1 }} \mathrm{HNO}_{3}+0.4 \% \mathrm{HAc}$. 


\section{Materials and Methods}

\subsection{Reagents and Samples}

All solutions were prepared with ultrapure water $(18.20 \mathrm{M} \Omega \mathrm{cm}$, Millipore, Darmstadt, Germany). Trace metal free nitric acid was obtained by purifying nitric acid (Merck, Darmstadt, Germany) using a sub-boiling distillation system. Standard stock solutions of YREEs (1000 ppm) were obtained from the National Institute of Metrology (Beijing, China). Working standards were prepared via serial dilutions of the stock solution with 0.02 mol L ${ }^{-1}$ purified $\mathrm{HNO}_{3}$ (equal to acidified sample $\mathrm{pH}$ 1.6). Ammonium acetate $\left(\mathrm{NH}_{4} \mathrm{Ac}\right)$ buffer solution was prepared by mixing $30 \mathrm{~mL}$ aqueous ammonia (Sinopharm Chemical Reagent Co., Nanjing, China) and $20 \mathrm{~mL}$ glacial acetate acid (HAc, Sinopharm Chemical Reagent Co., Nanjing, China) and diluting to $1 \mathrm{~L}$ using ultrapure water; the $\mathrm{pH}$ was subsequently adjusted to $5.5 \pm 0.2$ with $\mathrm{HAc}$ or $\mathrm{NH}_{4} \mathrm{OH}$ [31]. The buffer solution was further purified to remove potential YREEs by passing it through a column packed with Toyopearl AF Chelate $650 \mathrm{M}^{\circledR}$ resin. Two Certified Reference Materials (SLEW-3 and CASS-4) were purchased from the National Research Council Canada (Ottawa, Canada). Estuarine samples (salinity of 2 and 15) collected from the Jiulong River Estuary and coastal seawater (salinity $=33$ ) collected from the South China Sea were used to optimize the method, All samples were acidified to $\mathrm{pH} \sim 1.6$ using purified $\mathrm{HNO}_{3}$ after filtered using $0.45 \mu \mathrm{m}$ polycarbonate membranes. Trace metal clean procedures were used for the water sample collection.

All reagents and samples were stored in fluorinated ethylene propylene, low-density polyethylene or polypropylene acid washed bottles (Nalgene, Rochester, NY, USA). The cleaning procedure for all labware is detailed in Wen et al. [43].

\subsection{Instrumentation}

An Agilent 7700 $\times$ ICP-MS (Agilent, Tokyo, Japan) operating in time-resolved-analysis mode was used for the measurement of YREEs. The ICP-MS was equipped with an octopole reaction/collision system which was employed to help overcome oxide and polyatomic interferences. The operating conditions were daily optimized with a $1 \mu \mathrm{g} \mathrm{L}-1$ tuning solution (Co, Y, In, Tl, Ce) in the eluting acid at a flow rate equal to the elution rate. The typical operating parameters are summarized in Table 4.

Table 4. Typical ICP-MS operating conditions.

\begin{tabular}{cc}
\hline Rf Power & $\mathbf{1 5 0 0 ~ \mathbf { ~ }}$ \\
\hline Plasma gas & $15.0 \mathrm{~L} \mathrm{~min}^{-1}$ \\
Auxiliary gas & $1.0 \mathrm{~L} \mathrm{~min}^{-1}$ \\
Carrier gas & $0.85 \mathrm{~L} \mathrm{~min}^{-1}$ \\
Collision gas (He) & $4.1 \mathrm{~mL} \mathrm{~min}^{-1}$ \\
Integration time & $0.1 \mathrm{~s} \mathrm{per} \mathrm{isotope}$ \\
Sampling depth & $8 \mathrm{~mm}{ }^{147} \mathrm{Sm}^{151} \mathrm{Eu}^{157} \mathrm{Gd}$ \\
Target isotopes & ${ }^{89} \mathrm{Y}^{139} \mathrm{La}^{140} \mathrm{Ce}^{141} \mathrm{Pr}^{143} \mathrm{Nd}^{169} \mathrm{Tm}^{174} \mathrm{Yb}^{175} \mathrm{Lu}$ \\
\hline
\end{tabular}

\subsection{FI System and FI-ICP-MS Analysis Procedure}

The construction of the FI system used in this study is shown in Figure 6. Apart from the metal free minicolumn assembly (MC-2CNME, Global FIA, Fox Island, WA, USA) with a tapered inner chamber ( $2 \mathrm{~cm}$ long with $27 \mu \mathrm{L}$ internal volume) packed with Toyopearl AF Chelate 650M ${ }^{\circledR}$ (particle size: 40-90 $\mu \mathrm{m}$; Tosoh Bioscience GmbH, Griesheim, Germany) resin and the T joint (i.d. $0.75 \mathrm{~mm}$, VICI, Houston, TX, USA), all other parts of the FI system were the same as those used in our previous study $[40,41]$. The FI system was controlled using a computer running LabVIEW program (National Instruments, Austin, TX, USA). The schematic of FI-ICP-MS procedure is given in Figure 6 and the optimized FI program is summarized in Table 5. 
Table 5. Typical flow injection program and valve position description.

\begin{tabular}{|c|c|c|c|c|c|}
\hline Step & Duration/s & Pump 1/mL $\min ^{-1}$ & Pump 2/mL min ${ }^{-1}$ & 8-Position Valve & 6-Way Valve \\
\hline Conditioning & 20 & 0.5 & 1.5 & 1 & A \\
\hline Loading & 180 & 0.5 & 2.0 & 1 & A \\
\hline Rinsing & 60 & 0.5 & 2.0 & 1 & A \\
\hline Eluting & 50 & 1.0 & 0 & 2 & B \\
\hline \multicolumn{6}{|c|}{ Return to conditioning } \\
\hline
\end{tabular}

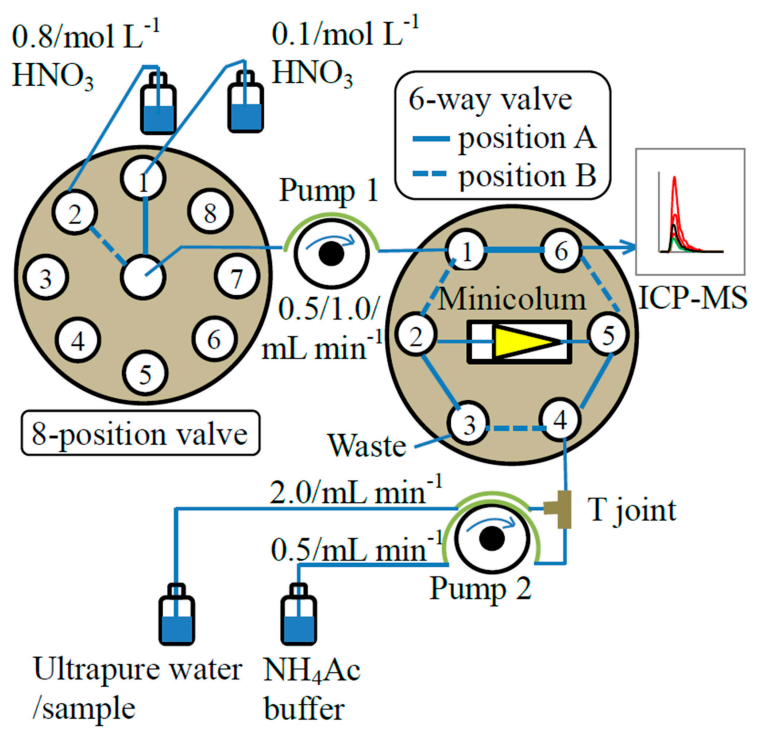

Figure 6. Schematic of the FI system and the FI-ICP-MS procedure.

A run cycle comprises four steps: step 1, conditioning, buffer solution and ultrapure water are mixed at the $\mathrm{T}$ joint and then passed through the minicolumn; step 2, loading, sample tube is placed into the sample bottle, sample ( $\mathrm{pH} ~ 1.6$ ) is online buffered to $\mathrm{pH} 5.5 \pm 0.2$ before entering the minicolumn and YREEs are retained on the column while the matrix salts pass to waste; step 3, rinsing, sample tube is transferred to the ultrapure water bottle and the mixture of buffer solution and ultrapure water is passed through the minicolumn to remove residual salts; step 4, 8-position valve is switched from position 1 to position 2 and 6-way valve is switched from position $A$ to position $\mathrm{B}, 0.8 \mathrm{~mol} \mathrm{~L}^{-1}$ $\mathrm{HNO}_{3}$ is pumped through the minicolumn in the reverse direction to elute the sequestered YREEs to the ICP-MS, and the data acquisition by the ICP-MS is manually activated at the same time. The elution profiles are recorded and the peak areas are integrated using the Agilent MassHunter workstation (Agilent, Santa Clara, CA, USA). The integration range was determined based on the comparison of YREEs signal intensity between the sample and the baseline $(0-5 \mathrm{cps})$. The concentrations of the YREEs are determined using both standard addition as well as external standard calibration (see details in Section 2.4. Calibration and effect of salinity).

\section{Conclusions}

An automated FI system coupled online with ICP-MS to determine YREEs in seawater was developed. The components of the FI system in this work are all commercially available and the FI system is easy and cheap to assemble. With low LODs $\left(0.002-0.078 \mathrm{ng} \mathrm{kg}^{-1}\right)$, the method only needs 6 $\mathrm{mL}$ of sample and achieves accurate and fast sample analysis $\left(11 \mathrm{~h}^{-1}\right)$, making the regular monitoring of YREEs in seawater affordable. The analytical results of YREEs in CASS-4 and SLEW-3 confirmed that the proposed method can provide reliable results. The proposed method has been successfully applied to the determination of YREEs in seawater from the Jiulong River Estuary and Taiwan Strait, 
and the procedure blank can be further reduced to meet the requirement of measurement of open ocean seawater by the further purification of $\mathrm{HNO}_{3}$ and the buffer. The developed FI system can also be used as a preconcentration manifold for the offline detection (batch method) of not only YREEs but also other transition metals ( $\mathrm{Fe}, \mathrm{Mn}, \mathrm{Cu}, \mathrm{Zn}$, etc.), and both the online and offline methods will be used in future work for trace metal detection in seawater.

Supplementary Materials: The following are available online, Table S1: Percentage of REEs peak area (\%) of different loading rates to peak area of $1.5 \mathrm{~mL} \mathrm{~min}^{-1}$. Table S2: Relative coefficients $\left(\mathrm{R}^{2}\right)$ between REEs peak areas and loading times. Table S3: REEs concentrations measured by the presented method from samples collected in the Jiulong River Estuary (water samples were collected in April 2015). Table S4: REEs concentrations measured by the presented method from samples collected in Taiwan Strait (seawaters were collected at the station C9, $22^{\circ} 07^{\prime} 13^{\prime \prime} \mathrm{N}, 118^{\circ} 24^{\prime} 41^{\prime \prime} \mathrm{E}$, in April 2014).

Acknowledgments: This work was financially supported by the project "Special Fund for Marine Scientific Research in the Public Interest-A Nearshore of Micro/Nano Particles Biological Ecological Effect Assessment Techniques and Demonstration Application" from State Oceanic Administration of China (No. 201505034). Ralph Sturgeon (National Research Council Canada) is thanked for polishing the English and giving valuable comments, which improved this manuscript.

Author Contributions: Zuhao Zhu and Airong Zheng conceived and designed the experiments. Zuhao Zhu performed the experiment and analyzed the data. Zuhao Zhu and Airong Zheng wrote the paper.

Conflicts of Interest: The authors declare no conflict of interest.

\section{References}

1. Elderfield, H.; Greaves, M.J. The rare earth elements in seawater. Nature 1982, 296, 214-219. [CrossRef]

2. Hatje, V.; Bruland, K.W.; Flegal, A.R. Determination of rare earth elements after pre-concentration using NOBIAS-chelate PA- $1^{\circledR}$ resin: Method development and application in the San Francisco Bay plume. Mar. Chem. 2014, 160, 34-41. [CrossRef]

3. Byrne, R.H.; Kim, K.-H. Rare earth element scavenging in seawater. Geochim. Cosmochim. Acta 1990, 54, 2645-2656. [CrossRef]

4. German, C.R.; Masuzawa, T.; Greaves, M.J.; Elderfield, H.; Edmond, J.M. Dissolved rare earth elements in the Southern Ocean: Cerium oxidation and the influence of hydrography. Geochim. Cosmochim. Acta 1995, 59, 1551-1558. [CrossRef]

5. Nozaki, Y.; Alibo, D.S. Importance of vertical geochemical processes in controlling the oceanic processes of dissolved rare earth elements in the northeastern Indian Ocean. Earth Planet. Sci. Lett. 2003, 205, 155-172. [CrossRef]

6. Zheng, X.-Y.; Plancherel, Y.; Saito, M.A.; Scott, P.M.; Henderson, G.M. Rare earth elements (REEs) in the tropical South Atlantic and quantitative deconvolution of their non-conservative behavior. Geochim. Cosmochim. Acta 2016, 177, 217-237. [CrossRef]

7. Barretto, P.M.C.; Fujimori, K. Natural analogue studies: Geology and mineralogy of Morro do Ferro, Brazil. Chem. Geol. 1986, 55, 297-312. [CrossRef]

8. Yan, X.-P.; Kerrich, R.; Hendry, M.J. Flow injection on-line group preconcentration and separation of (ultra) trace rare earth elements in environmental and geological samples by precipitation using a knotted reactor as a filterless collector for inductively coupled plasma mass spectrometric determination. J. Anal. At. Spectrom. 1999, 14, 215-221.

9. Vicente, O.; Padro, A.; Martinez, L.; Olsina, R.; Marchevsky, E. Determination of some rare earth elements in seawater by inductively coupled plasma mass spectrometry using flow injection preconcentration. Spectrochim. Acta B 1998, 53, 1281-1287. [CrossRef]

10. Bau, M.; Dulski, P. Anthropogenic origin of positive gadolinium anomalies in river waters. Earth Planet. Sci. Lett. 1996, 143, 245-255. [CrossRef]

11. Elbaz-Poulichet, F.; Seidel, J.-L.; Othoniel, C. Occurrence of an anthropogenic gadolinium anomaly in river and coastal waters of Southern France. Water Res. 2002, 36, 1102-1105. [CrossRef]

12. Fu, Q.; Yang, L.; Wang, Q. On-line preconcentration with a novel alkyl phosphinic acid extraction resin coupled with inductively coupled plasma mass spectrometry for determination of trace rare earth elements in seawater. Talanta 2007, 72, 1248-1254. [CrossRef] [PubMed] 
13. Shellock, F.G.; Spinazzi, A. MRI Safety Update 2008: Part 1, MRI contrast agents and nephrogenic systemic fibrosis. Am. J. Roentgenol. 2008, 191, 1129-1139. [CrossRef] [PubMed]

14. Kulaksız, S.; Bau, M. Anthropogenic dissolved and colloid/nanoparticle-bound samarium, lanthanum and gadolinium in the Rhine River and the impending destruction of the natural rare earth element distribution in rivers. Earth Planet. Sci. Lett. 2013, 362, 43-50. [CrossRef]

15. Shabani, M.B.; Akagi, T.; Shimizu, H.; Masuda, A. Determination of trace lanthanides and yttrium in seawater by inductively coupled plasma mass spectrometry after preconcentration with solvent extraction and back-extraction. Anal. Chem. 1990, 62, 2709-2714. [CrossRef]

16. Lawrence, M.G.; Kamber, B.S. Rare earth element concentrations in the natural water reference materials (NRCC) NASS-5, CASS-4 and SLEW-3. Geostand. Geoanal. Res. 2007, 31, 95-103. [CrossRef]

17. Labrecque, C.; Lariviere, D. Quantification of rare earth elements using cloud point extraction with diglycolamide and ICP-MS for environmental analysis. Anal. Methods 2014, 6, 9291-9298. [CrossRef]

18. Greaves, M.J.; Elderfield, H.; Klinkhammer, G.P. Determination of the rare earth elements in natural waters by isotope-dilution mass spectrometry. Anal. Chim. Acta 1989, 218, 265-280. [CrossRef]

19. Bayon, G.; Birot, D.; Bollinger, C.; Barrat, J.A. Multi-element determination of trace elements in natural water reference materials by ICP-SFMS after Tm addition and iron co-precipitation. Geostand. Geoanal. Res. 2010, 35, 145-153. [CrossRef]

20. Freslon, N.; Bayon, G.; Birot, D.; Bollinger, C.; Barrat, J.A. Determination of rare earth elements and other trace elements ( $\mathrm{Y}, \mathrm{Mn}, \mathrm{Co}, \mathrm{Cr}$ ) in seawater using Tm addition and $\mathrm{Mg}(\mathrm{OH})_{2}$ co-precipitation. Talanta 2011, 85, 582-587. [CrossRef] [PubMed]

21. Zheng, X.-Y.; Yang, J.; Henderson, G.M. A robust procedure for high-precision determination of rare earth element concentrations in seawater. Geostand. Geoanal. Res. 2014, 39, 277-292. [CrossRef]

22. Zhang, T.; Shan, X.; Liu, R.; Tang, H.; Zhang, S. Preconcentration of rare earth elements in seawater with poly(acrylaminophosphonic dithiocarbamate) chelating fiber prior to determination by inductively coupled plasma mass spectrometry. Anal. Chem. 1998, 70, 3964-3968. [CrossRef]

23. Wen, B.; Shan, X.; Xu, S. Preconcentration of ultratrace rare earth elements in seawater with 8-hydroxyquinoline immobilized polyacrylonitrile hollow fiber membrane for determination by inductively coupled plasma mass spectrometry. Analyst 1999, 124, 621-626. [CrossRef]

24. Haley, B.A.; Klinkhammer, G.P. Complete separation of rare earth elements from small volume seawater samples by automated ion chromatography: Method development and application to benthic flux. Mar. Chem. 2003, 82, 197-220. [CrossRef]

25. Zhu, Y.; Itoh, A.; Fujimori, E.; Umemura, T.; Haraguchi, H. Determination of rare earth elements in seawater by ICP-MS after preconcentration with a chelating resin-packed minicolumn. J. Alloys Compd. 2006, 408-412, 985-988. [CrossRef]

26. Karadas, C.; Kara, D.; Fisher, A. Determination of rare earth elements in seawater by inductively coupled plasma mass spectrometry with off-line column preconcentration using 2,6-diacetylpyridine functionalized Amberlite XAD-4. Anal. Chim. Acta 2011, 689, 184-189. [CrossRef] [PubMed]

27. Zereen, F.; Yilmaz, V.; Arslan, Z. Solid phase extraction of rare earth elements in seawater and estuarine water with 4-(2-thiazolylazo) resorcinol immobilized Chromosorb 106 for determination by inductively coupled plasma mass spectrometry. Microchem. J. 2013, 110, 178-184. [CrossRef] [PubMed]

28. Rodriguez, J.A.; Hernandez, P.; Salazar, V.; Castrillejo, Y.; Barrado, E. Amperometric biosensor for oxalate determination in urine using sequential injection analysis. Molecules 2012, 17, 8859-8871. [CrossRef] [PubMed]

29. Halicz, L.; Gavrieli, I.; Dorfman, E. On-line method for inductively coupled plasma mass spectrometric determination of rare earth elements in highly saline brines. J. Anal. At. Spectrom. 1996, 11, 811-814. [CrossRef]

30. Benkhedda, K.; Infante, H.G.; Ivanova, E.; Adams, F.C. Determination of sub-parts-per-trillion levels of rare earth elements in natural waters by inductively coupled plasma time-of-flight mass spectrometry after flow injection on-line sorption preconcentration in a knotted reactor. J. Anal. At. Spectrom. 2001, 16, 995-1001. [CrossRef]

31. Willie, S.N.; Sturgeon, R.E. Determination of transition and rare earth elements in seawater by flow injection inductively coupled plasma time-of-flight mass spectrometry. Spectrochim. Acta B 2001, 56, 1707-1716. [CrossRef] 
32. Hirata, S.; Kajiya, T.; Aihara, M.; Honda, K.; Shikino, O. Determination of rare earth elements in seawater by on-line column preconcentration inductively coupled plasma mass spectrometry. Talanta 2002, 58, 1185-1194. [CrossRef]

33. Kajiya, T.; Aihara, M.; Hirata, S. Determination of rare earth elements in seawater by inductively coupled plasma mass spectrometry with on-line column pre-concentration using 8-quinolinole-immobilized fluorinated metal alkoxide glass. Spectrochim. Acta B 2004, 59, 543-550. [CrossRef]

34. Wang, Z.-H.; Yan, X.-P.; Wang, Z.-P.; Zhang, Z.-P.; Liu, L.-W. Flow injection on-line solid phase extraction coupled with inductively coupled plasma mass spectrometry for determination of (ultra) trace rare earth elements using maleic acid grafted polytetrafluoroethylene fibers as sorbent. J. Am. Soc. Mass Spectrom. 2006, 17, 1258-1264. [CrossRef] [PubMed]

35. Zhu, Y.; Umemura, T.; Haraguchi, H.; Inagaki, K.; Chiba, K. Determination of REEs in seawater by ICP-MS after on-line preconcentration using a syringe-driven chelating column. Talanta 2009, 78, 891-895. [CrossRef] [PubMed]

36. Hathorne, E.C.; Haley, B.; Stichel, T.; Grasse, P.; Zieringer, M.; Frank, M. Online preconcentration ICP-MS analysis of rare earth elements in seawater. Geochem. Geophys. Geosyst. 2012, 13. [CrossRef]

37. Arslan, Z.; Paulson, A.J. Solid phase extraction for analysis of biogenic carbonates by electrothermal vaporization inductively coupled plasma mass spectrometry (ETV-ICP-MS): An investigation of rare earth element signatures in otolith microchemistry. Anal. Chim. Acta 2003, 476, 1-13. [CrossRef]

38. Shelley, R.U.; Zachhuber, B.; Sedwick, P.N.; Worsfold, P.J.; Lohan, M.C. Determination of total dissolved cobalt in UV-irradiated seawater using flow injection with chemiluminescence detection. Limnol. Oceanogr. Methods 2010, 8, 352-362. [CrossRef]

39. Sturgeon, R.E.; Willie, S.N.; Yang, L.; Greenberg, P.; Spatz, R.O.; Chen, Z.; Scriver, C.; Clancy, V.; Lam, J.W.H.; Thorrold, S. Certification of a fish otolith reference material in support of quality assurance for trace element analysis. J. Anal. At. Spectrom. 2005, 20, 1067-1071. [CrossRef]

40. Zhu, Z.; Zheng, A. Determination of rhenium in seawater from the Jiulong River Estuary and Taiwan Strait, China by automated flow injection inductively coupled plasma-mass spectrometry. Anal. Lett. 2017, 50, 1422-1434. [CrossRef]

41. Zhu, Z.; Zheng, A. Automated flow injection coupled with ICP-MS for the online determination of trace silver in seawater. Spectroscopy 2017, 32, 50-59.

42. Pourmand, A.; Dauphas, N.; Ireland, T.J. A novel extraction chromatography and MC-ICP-MS technique for rapid analysis of REE, Sc and Y: Revising CI-chondrite and Post-Archean Australian Shale (PAAS) abundances. Chem. Geol. 2012, 291, 38-54. [CrossRef]

43. Wen, L.-S.; Stordal, M.C.; Tang, D.; Gill, G.A.; Santschi, P.H. An ultraclean cross-flow ultrafiltration technique for the study of trace metal phase speciation in seawater. Mar. Chem. 1996, 55, 129-152. [CrossRef]

Sample Availability: Samples of the those seawater samples from Jiulong River Estuary and Taiwan Strait are available from the authors, the other samples and reagents are not available from the authors.

(C) 2018 by the authors. Licensee MDPI, Basel, Switzerland. This article is an open access article distributed under the terms and conditions of the Creative Commons Attribution (CC BY) license (http:// creativecommons.org/licenses/by/4.0/). 